\title{
Carson McCullers's Androgynous Image Inquiry
}

\author{
Cai Lanlan ${ }^{1}$, Zhuang Zhiqiang ${ }^{2,} *$ \\ ${ }^{1}$ School of Foreign Languages, Quanzhou Normal University, Quanzhou, Fujian, P.R.China,362000 \\ ${ }^{2}$ School of Foreign Languages, Minnan Normal University, Zhangzhou, Fujian, P.R.China,363000 \\ zhuangsir@163.com
}

Keywords: Carson McCullers; androgyny; social background; life experience; enlightenment

\begin{abstract}
Carson McCullers is one of the famous twentieth- Century South American female writers, whose works are emotional and good at reflecting the era of tragedy with the androgynous images. The biography of Carson McCullers and representative works are first introduced, and then comes the interpretation of the three types of the sex marginal characters, as well as in-depth analysis of the androgynous image features, and finally the characterization of "androgyny" image formation is discussed based on the social background, the author's experience and other aspects.
\end{abstract}

\section{Introduction}

Carson McCullers, a unique southern American writer in the twentieth century, despite life of agony, created a large number of outstanding works of specific style in her short life. The characters in her writings lived in the period of great social changes in the south, and the ways of people's communication changed too. Both men and women clearly felt the loneliness caused by spiritual isolation, spiritual emptiness and lack of initiative. In Carson McCullers's novels, characters of gender are even difficult to determine. Private Williams and Captain Penderton, for example, escape from the female side, and on the other hand, they pursue the femininity, so their fate is the symbol of deformity of the features of the times.

\section{Overview of Androgyny}

In Carson McCullers's novels, most of the protagonists are out of the clear definition of gender with androgynous features, and an important cause of this phenomenon is rooted in the patriarchal society. In her works such as The Ballad of the Sad Cafe, The Heart is a Lonely Hunter and The Member of the Wedding, there are androgynous people. Androgyny is the union of men and women, biologically understood as having both mature male and female sexual organs. In terms of psychology, it refers to the personality of men and women. In the concrete application, people emphasize the symbolic significance as well as the psychology characteristics. Being an important concept in the twentieth century as a feminist critique, androgyny is billed as a kind of value, and considered to be beyond the gender opposition, containing the perfect "people" concept of male and female excellent quality, and expressing the desire of feminists for the gender equality and harmonious coexistence.

Androgyny applied in literature for the first time from the standpoint of women was created by a female English writer Virginia Woolf, who conceived a general criterion for literary criticism of the androgynous, half male and half female mind. She believes that human temperament should be composed of two aspects, and is influenced and dominated by two forces, namely, male factors and female factors, and these two factors have different advantages in different genders. In men's minds, men are generally the dominant factor, while women's minds are the opposite. In the normal and comfortable living condition, two factors should be in harmony with each other. Woolf takes the equality between men and women as the starting point, studies the gender differences in the patriarchy and the uniqueness of women's existence, and therefore puts forward the idea of subverting 
the pattern of "two oppositions". McCullers's androgyny completely overturns Woolf's idea, in which the main causes of gender roles of duality are the opposite of the patriarchal society from the oppression of women, or by refusing to compromise and trying to retain the characteristics of androgyny to adulthood, and eventually leading to the tragedy of life.

\section{Shaping the Image of McCullers's Androgyny Works}

Carson McCullers's works, construct a lonely silence, singular style of the south, as well as create many popular and unique characters, and through these popular and unique characters, many of the inherent life propositions are discussed. In recent years, in the interpretation of the theory of feminism literature, Carson McCullers's works are abundant, and show the eternal charm of literature. McCullers's works pay more attention to disadvantages in gender, race, sexual orientation and class of people, usually expressed on bisexual transvestite and bisexual sympathy, showing the author's concerns for gender identity.

\section{"Tomboy" Gender Ambiguity}

The so-called "tomboy" refers to the following: girls are like boys in character, appearance, and dress, and the female sex biased habit leads to the offbeat perception of women, the false men. Except for the bodies of the girls, they are same as the male and the sexual orientation and love are different from girls, regarding boys just as brothers. There are exceptions, some taking themselves as gays in love with boys, that is, bisexual. McCullers's "tomboys" not only tend to be masculine in dress, but the behaviors deviate from normal women. Their androgyny is mainly in adolescence, because their sexual orientation has not really been completed at this time. Representatives such as French in The Member of the Wedding, Mick in The Heart is a Lonely Hunter, and Amelia in The Ballad of the Sad Cafe, who are female but have obvious characteristics of the male. In the patriarchal society, they aspire to become men, and bravely go against the patriarchal challenges, but in the patriarchal society under the rule of traditional culture and repression of the south, the hope is finally shattered as they have to succumb to the pressure, and finally give up their pursuit.

French and Mick, just entering puberty at twelve or thirteen years old, have reached a height of 1.75 meters. The book describes "if she grows up to eighteen years old, still ahead waiting for five years and two months. In that case, unless she can stop herself, she will be over nine feet tall." They think that the female body is a burden for growth, and this trait is hard to bear when it is combined with masculinity. In order to get rid of their dissatisfaction, they wear T-shirts, shorts and shoes, join in the violent sports just like boys, and actively get close to the boys' behaviors. They do not like their own female characters, so they often show their own special characteristics through different experiences from other women. "Her shoulders were narrow and her legs were too long. She wore a pair of blue shorts, a singlet, and bare feet. Her hair was cut like a boy, and it was not long before it was cut off." And Mick is dismissive of her sister's frantic pursuit of feminine beauty. Instead, she looks forward to being a boy every day. "I wish I could move to Bill's house." Through the "tomboy" image, McCullers breaks the traditional concept of gender and sex, breaks the sexual orientation based on heterosexual as the core, and makes the social gender, sex of the internal consistency of the relationship broken.

McCullers completely alienates the dual sex world, who portrays through "tomboy" image, putting in mixed gender status to break the image of female sex fantasy, and the so-called "inborn" and "natural" gender view is completely broken. French likes dressing up as Mexicans to play tricks on his passengers and has great dreams. Mick dreams of becoming a world-class composer like Mozart, directing herself in a man's evening dress. French is eager to become a woman captain, travelling around the world by plane and train as a member of the whole world. However, these dreams are doomed to be unable to realize. Poor and limited by sex, it is difficult to find a well paid part-time job, which leads to Mick's lack of money to buy the piano. French is rejected to join the army because she is female, and she longs for more powerful groups rather than the weak and lonely ones after the frustration, but her relatives do not know her big dreams, so her dreams are eventually disillusioned. 
Due to the "restricted" female body, French and Mick are eventually restricted in the lonely town, wandering all the day. Without freedom of action like men, they have to put the dreams in their hearts, watch them fade, gradually compromise to the reality, give up the body of the male temperament, and are finally killed by the patriarchy society.

Emilia in The Ballad of the Sad Cafe is French and Mick's adult version, who is tough, strong, independent, diligent, kind-hearted, gentle and considerate, --- a social role and gender of the wrong. Her strange behavior and living habits are not being understood by the patriarchal society. She is tall and dark, and hence people consider her unapproachable. She is good at woodwork, brewing, business, financing and other men's work, but meanwhile she is withdrawn, difficult to get along with, let alone her history of two affections. Her first marriage lasts for only 10 days and she is knocked out of the house in humiliation, becoming the local people's joke. A few years later, however, she falls in love with a disabled, ugly hunchback, trying to please her sweetheart. Obviously, all these deeply violate female ethics and traditional standards, so Amelia is not forgiven, and even ends up tragically as a model for the patriarchal society to punish nontraditional female.

\section{A Feminine Temperament That Cannot Escape}

In McCullers's Reflections in a Golden Eye, Private Williams takes feminine as the most terrible diseases in women, and fears that the infectious disease will be transmitted to the male, thus leading to the male tragic ending, so after the age of eight, he never contacts female soldiers. But, contrary to this, he does not reject female animals, such as hugging the mare and milking the cows. In his view, women are inferior to men. Captain Penderton is a sex killer, and he seems to be slapped in the face when seeing his wife naked. The male created by the author fear to see the female body, and they are more infatuated with the same sex while fleeing women, but they show their feminine temperament in contradiction. Lymon attaches Marvin like a philandering stupid woman, who calls Marvin to get up in a coaxing voice, catches Marvin's attention through some feminine movements, and even like a woman touches Marvin's trouser legs and twists his ears, while Singer in The Heart is a Lonely Hunter welcomes the visitors with smiles like a mistress. Their behaviors have been gradually penetrated with female temperament. In short, they hate all the female temperaments, but however masculine they show, they always unconsciously imitate female temperament, unable to avoid the feminine existence. It is this inescapable femininity that makes them finally become victims of patriarchal society. In the patriarchal society of male culture independent personality under the tough limit, Singer eventually gives all the feelings to Antonapoulos, a deaf and retarded man. When Antonapoulos is sent to a mental hospital, Singer's world is hollowed out, and he often wanders in the street in his solitude, recalling their happy times, but no one would understand this kind of love. Only by getting together with Antonapoulos can Singer freely express his own characteristics, anxiety, worry, and happiness. With Antonapoulos sent to a mental hospital and finally dying, Singer's spiritual home completely collapses, his spiritual world is empty, and he chooses to take his own life at last. On the other hand, Lymon due to the influence of inner femininity has an almost crazy love for Marvin, but in the male-centered patriarchal society, this love does not get any return, and even becomes the target of criticism. Actually, Marvin does not fall in love with Lymon, and in the end Lymon is sold to the circus as a freak.

In McCullers's works, quite a few male characters such as Singer and Lymon dislike women and reject all the female temperaments, but that "sexual perverts own androgynous features" cannot be avoided. They may be masculine in disguise with exaggeration and surface behaviors, but cannot control the female temperaments in their hearts, and eventually they become victims of the patriarchal society.

\section{The Causes of Androgyny Created by the Author}

\section{Era Background}


McCullers lived through 1940s-50s, when American educational, political and cultural fields were influenced by exclusive and anti-communist Mccarthyism. In the meanwhile, all the "non normal" sex people, transsexualism, homosexuality and other gender marginal people were discriminated against and oppressed. During the cold war, they became scapegoats, and homosexuals were obviously played low upon when they were looking for jobs, and harassed by the states and local organizations. During this period, all the works and books on gays and lesbines were unable to express or even suggest homosexual existence. And most homosexuals were laid off and unemployed because of homosexual discrimination. Deprived of the basic rights of citizens, the American mainstream comprehensively disdains and rejects homosexuality groups. In this context, due to her own bisexuality, McCullers paid more attention to the gender of vulnerable groups, and created representative images of Androgyny in her works.

\section{Personal Experiences}

Throughout McCullers's novels, her life experience can be seen in general. Her adolescent shadow, for example, can be displayed in Mick and Frankie, and her adult emotional entanglements in Emilia. McCullers once said that everything in her novels was her experience or what was going to happen to her, so writing became an important means of catharsis and psychotherapy. Her childhood and girlhood were mainly spent in South Georgia. Her father was a watch repairman in a jewelry business, while her mother was well educated, and good at making stories. In her childhood, her mother cared for her too much, taking her as a genius and placing high hopes on her. At the age of 13, she decided to become a pianist and attached great importance to relations with the Mary Tucker family, but when she left owing to the rheumatic fever, she decided to give up the piano and become a writer. The Member of the Wedding is derived from the feeling in this period.

McCullers's girlhood is very similar to French and Mick, and the striking similarity in the works is her height. She is afraid to become the tallest girl in the world, so she demonstrates her masculinity by male dress-up. She likes to wear men's trousers, cotton pants, men's jackets and so on. At the age of 17, McCullers came to New York and began her writing. At the age of 22, she finished The Heart is a Lonely Hunter and embarked on the road of literary creation. McCullers's life is very rough. She suffered from rheumatic fever when 15 years old, but got misdiagnosis and mistreatment, and after three strokes, she was paralyzed in bed at the age of 29. In addition, her unstable sexual orientation and complex emotional entanglements ultimately made her hysterical and psychiatrical, and her husband's Dutch act was undoubtedly the last straw that overwhelmed her. At the age of 50, McCullers went through the agony of dying in loneliness and criticism.

\section{Conclusion}

Carson McCullers's Androgyny in shaping the images has a direct link to her personal experience and life background, breaking the traditional social definition of gender, and the characters in the works are finally treated as "outcasts", resulting in the shattered dreams. In a word, in the patriarchal society, the harmony of androgyny is a mirage, only serving as an indictment and an ideal.

\section{Acknowledgements}

Social science project of Fujian Provincial Education Department: the social harmony logic and its significance of "androgyny" literature view, item number JA12233S.

\section{References}

[1] Virginia Spencer Carle. A Lonely Hunter: Carson McCullers[M]. Shanghai: Shanghai Sanlian Publishing House, 2006.

[2] Virginia. Woolf. Essays. On novels and novelists [M]. Shanghai: Shanghai Translation Publishing House, 2000. 
[3] Carson McCullers. The Heart is a Lonely Hunter [M]. translated by Chen Xiaoli. Shanghai: Sanlian Bookstore, 2009.

[4] Carson McCullers. Reflections in a Golden Eye [M]. translated by Chen Li. Shanghai: Sanlian Publishing House, 2009.

[5] Carson McCullers. The Member of the Wedding [M]. translated by Zhou Yujun. Shanghai: the Joint Publishing Company, 2009.

[6] Carson McCullers. The Ballad of the Sad Cafe [M]. translated by Li Wenjun. Shanghai: the Joint Publishing Company, 2009. 